\title{
Synthesis of amino-functionalized MIL-101(Cr) as high performance HF gas sensor
}

\author{
Yuetao $\mathrm{Wu}^{1}$, Yanli $\mathrm{Liu}^{1 *}$, Jiaqiang $\mathrm{X} \mathrm{u}^{12^{*}}$ \\ 1 College of Materials Science and Engineering, Hunan University, Changsha 410082, China \\ 2 NEST Lab, Department of chemistry, College of Science, Shanghai University, Shanghai, 200444, \\ China. \\ *E-mail: liuyanli718@pku.edu.cn; xujiaqiang@shu.edu.cn
}

\begin{abstract}
:
Metal-organic frameworks have attracted much attention because of their potential applications in many fields such as catalysis, adsorption, sensors, and environmental remediation due to their controllable composition, structure and pore size. In this work, The Amino-functionalized metal-organic framework $\mathrm{NH}_{2}-\mathrm{MIL}-101(\mathrm{Cr})$, Containing 2-aminobenzene-1,4-dicarboxylate as the linker, has been synthesized. The morphologies, microstructures and compositional characteristics of the $\mathrm{NH}_{2}-\mathrm{MIL}-$ $101(\mathrm{Cr})$ were sufficiently examined by X-ray diffraction (XRD), nitrogen sorption analysis, scanning electron microscopy (SEM), and transmission electron microscope (TEM). In this study, a hydrogen fluoride sensor was fabricated by drop-casting a $\mathrm{NH}_{2}-\mathrm{MIL}-101(\mathrm{Cr})$ onto a quartz crystal microbalance (QCM). The sensor were investigated under different concentrations of hydrogen fluoride gas from $500 \mathrm{ppb}$ to $15 \mathrm{ppm}$ at room temperature. Upon exposure to hydrogen fluoride gas, the oscillation frequency of the QCM decreased immediately. The sensor can be regenerated by purging it with nitrogen gas, indicating reversibility of the response. The experimental results showed that the hydrogen fluoride gas sensor has a quite sensitive response, good repeatability and selectivity.
\end{abstract}

Key words: $\mathrm{NH}_{2}-\mathrm{MIL}-101(\mathrm{Cr})$, Metal-organic frameworks, hydrogen fluoride, gas sensor, Quartz Crystal Microbalance

\section{Results and Discussion of HF sensing performance}

Fig. 1 is the X-ray powder diffraction (XRD) patterns of $\mathrm{NH}_{2}-\mathrm{MIL}-101(\mathrm{Cr})$. The peaks position is similarity with MIL-101(Cr) indicated that the presence of $-\mathrm{NH}_{2}$ group in the organic linker did not change the structure of MIL101(Cr).

Figure 2 presents the FTIR spectra of $\mathrm{NH}_{2}$ MIL-101(Cr). The peaks at 3456 and $3371 \mathrm{~cm}^{-1}$ can be assigned to asymmetric and symmetric vibration of the amino groups, which confirm the introducing of the amino group $\left(-\mathrm{NH}_{2}\right)$ to the organic ligand. Strong absorption peaks did not occur ranging $1680-1720 \mathrm{~cm}^{-1}$, then this further reveals that the $-\mathrm{COOH}$ in 2-amin-oterephthalic acid coordinated with chromium ions to form metal-organic framework structure.

Fig.3 is the response curves of QCM gas sensors modified by $\mathrm{NH}_{2}-\mathrm{MIL}-101(\mathrm{Cr})$ to different HF concentrations. The curves show that the sensors have a quick signal response in a 500ppb-15ppm HF gas environment. All responses were similar in shape, and with the increase of the concentration of HF gas, the frequency response signal is increased.

Fig.4 exhibits the typical sensor response to 2.5-12.5 ppm levels of HF gas, where it is seen that the frequency shift was more than $75 \mathrm{~Hz}$ at $2.5 \mathrm{ppm}$. With increasing the concentration, the frequency shift tended to increase, indicating enhanced sensitivity.

Fig. 5 shows the detailed comparison of three gas response, the different magnitude of frequency shift to HF $(0.5 \mathrm{ppm}, 1 \mathrm{ppm}, 2.5 \mathrm{ppm}$, 5ppm, 10ppm, 15ppm ), $\mathrm{CO}_{2}$ (4ppm, 8ppm, 20ppm, 40ppm, 80ppm, 120ppm), $\mathrm{H}_{2} \mathrm{~S}$ (4ppm, 8ppm, 20ppm, 40ppm, 80ppm,120ppm) indicates good selectivity to HF gas. 
In summary, QCM sensors functionalized with $\mathrm{NH}_{2}-\mathrm{MIL}-101(\mathrm{Cr})$ was designed in a simple and reproducible way for the detection of $\mathrm{HF}$ gas. They have significant response to $\mathrm{HF}$, and frequency shift reaches $-28 \mathrm{~Hz}$ at a $\mathrm{HF}$ concentration of $500 \mathrm{ppb}$, which indicate that $\mathrm{NH}_{2}-\mathrm{MIL}-101(\mathrm{Cr})$-based QCM sensor could be a new avenue for detection of HF gas in air.

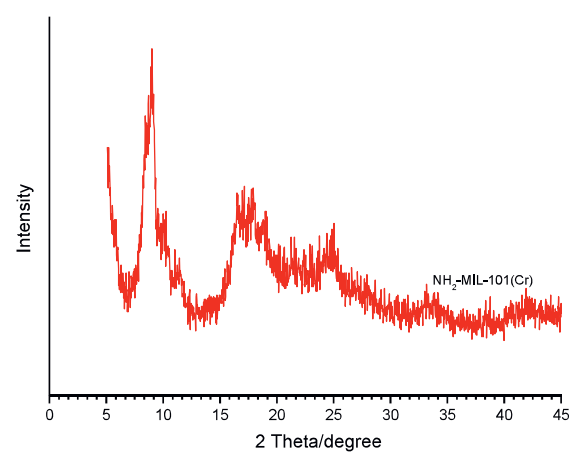

Fig. 1. XRD patterns of $\mathrm{NH}_{2}-\mathrm{MIL}-101(\mathrm{Cr})$

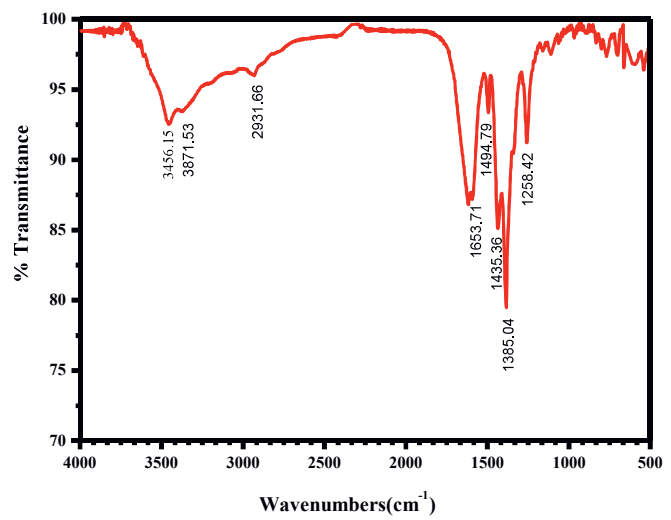

Fig. 2 FTIR spectra of the $\mathrm{NH}_{2}-\mathrm{MIL}-101(\mathrm{Cr})$

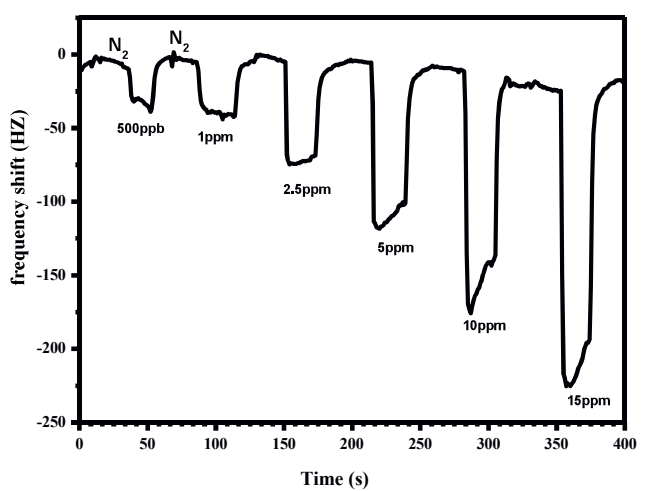

Fig.3 Response curves of QCM gas sensor to the different concentrations of HF

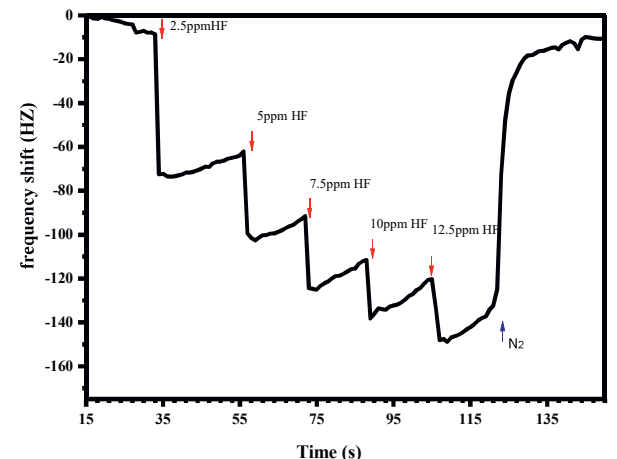

Fig.4 The typical sensor response to 2.5-12.5 ppm levels of HF

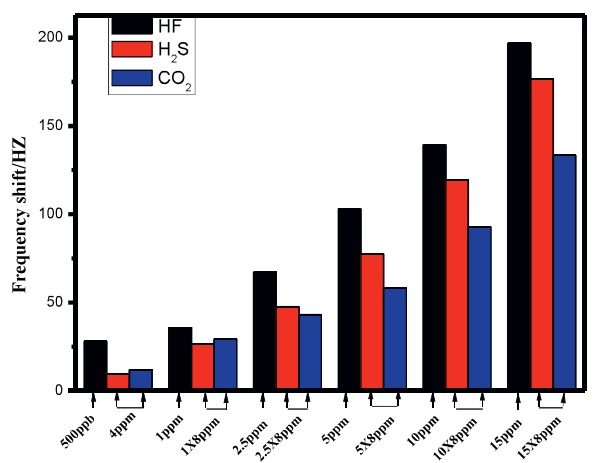

Fig.5 Frequency shifts of as-prepared $\mathrm{NH}_{2}-\mathrm{MIL}$ 101 $(\mathrm{Cr})$ functionalized QCM resonator upon exposure to $\mathrm{HF}, \mathrm{H}_{2} \mathrm{~S}, \mathrm{CO}_{2}$ with different concentration

\section{Acknowledgement}

Acknowlegement: The authors thank the project support of the Shanghai Committee of Science and Technology, China(Grant No. 17010500500 ) and National Natural Science Foundation of China (Grant 61527818). The authors also acknowledge the support of Shanghai Education Commission (Peak Discipline Construction).

\section{Reference}

[1] N. Tian, Q. Jia, H. Su, Y. Zhi, A. Ma, J. Wu, S. Shan, The synthesis of mesostructured NH2-MIL$101(\mathrm{Cr})$ and kinetic and thermodynamic study in tetracycline aqueous solutions, Journal of Porous $\begin{array}{lll}\text { Materials } 23 \text { (2016) 1269-1278. DOI:10.10 } & 0\end{array}$ 07/s10934-016-0186-z

[2] D. Jiang, L.L. Keenan, A.D. Burrows, K.J. Edler, Synthesis and post-synthetic modification of MIL$101(\mathrm{Cr})-\mathrm{NH} 2$ via a tandem diazotisation process, Chem Commun (Camb) 48 (2012) 12053-12055. DOI: $10.1039 / \mathrm{c} 2 \mathrm{cc} 36344 \mathrm{e}$

[3] L. Gao, C.Y. Li, H. Yung, K.Y. Chan, A functionalized MIL-101(Cr) metal-organic framework for enhanced hydrogen release from ammonia borane at low temperature, Chem Commun (Camb) 49 (2013) 10629-10631. DOI: $10.1039 / c 3 c c 45719 b$ 